\title{
Constitutive equations of a ballistic steel alloy as a function of temperature
}

\author{
L. Berkovic ${ }^{1}$, A. Chabotier ${ }^{2}$, F. Coghe ${ }^{2}$, and L. Rabet ${ }^{1}$ \\ ${ }^{1}$ Royal Military Academy, Department of Civil and Material Engineering, 1000 Brussels, Belgium \\ ${ }^{2}$ Royal Military Academy, Department of Weapon Systems and Ballistics, 1000 Brussels, Belgium
}

\begin{abstract}
In the present work, dynamic tests have been performed on a new ballistic steel alloy by means of split Hopkinson pressure bars (SHPB). The impact behavior was investigated for strain rates ranging from 1000 to $2500 \mathrm{~s}^{-1}$, and temperatures in the range from -196 to $300^{\circ} \mathrm{C}$. A robotized sample device was developed for transferring the sample from the heating or cooling device to the position between the bars. Simulations of the temperature evolution and its distribution in the specimen were performed using the finite element method. Measurements with thermocouples added inside the sample were carried out in order to validate the FEM simulations. The results show that a thermal gradient is present inside the sample; the average temperature loss during the manipulation of the sample is evaluated. In a last stage, optimal material constants for different constitutive models (Johnson-Cook, Zerilli-Amstrong, Cowper-Symonds) has been computed by fitting, in a least square sense, the numerical and experimental stress-strain curves. They have been implemented in a hydrocode for validation using a simple impact problem: an adapted projectile geometry with a truncated nose (.50 calibre fragment simulating projectiles) was fired directly against an armor plate. The parameters of the selected strength and failure models were determined. There is a good correspondence between the experimental and computed results. Nevertheless, an improved failure model is necessary to get satisfactory computed residual projectile velocities.
\end{abstract}

\section{Introduction}

This study aims to characterize the dynamic behavior of a metal alloy used for ballistic protection at high strain rates in a temperature range from $-196{ }^{\circ} \mathrm{C}$ up to $300^{\circ} \mathrm{C}$. The mechanical behavior of the material can be significantly different as a function of temperature. For modeling the impact of a projectile under those conditions, a finite element model (FEM) needs an adapted material model to describe the correct material behavior. Widely used models applied in FEM are the constitutive model of JohnsonCook, Zerilli-Amstrong and Cowper-Symonds. The final objective is to study the influence of the temperature and the strain rate on the behavior of metallic protective materials against typical ballistic threats. The alloy tested is a ballistic steel alloy in development with a Brinell Hardness Number (BHN) around 450.

\section{The split Hopkinson pressure bar (SHPB)}

The split Hopkinson pressure bars (SHPB) allow for a straightforward method to study material properties at high strain rates [2]. The SHPB apparatus consists of two long bars made of maraging steel, each having a length of 2 meter and a diameter of 3 centimeters [10]. A cylindrical sample of the material to be tested is put between the bars. A 40 centimeters length striker made of the same steel and with the same diameter as the bars is accelerated against the input bar causing an elastic wave to propagate through the bar and a plastic wave to propagate through the sample. By measuring the strains in the bars using strain gauges, the stress, strain and strain rate history of the sample can be calculated [8].
For tests above room temperature, a robotized sampleheating device was developed. The robot brings the sample into a furnace at a temperature above the aimed testing temperature. The sample is heated for $30 \mathrm{~s}$. Subsequently the robot places the sample against a thermocouple for measuring its exact temperature. Here the temperature drops until the target temperature is reached. At that moment the sample is quickly brought between the two bars for the actual dynamic test. The device is shown on Fig. 3.

For tests at low temperature, the material must be cooled. The sample is put into liquid nitrogen (below the aimed testing temperature). The sample is taken out and the temperature increases until the target temperature is reached. At this moment, the sample is quickly brought between the two bars for the actual dynamic test. (Fig. 2)

Because of the non-negligible delay between the positioning of the sample between the bars and the actual test, the evolution of the temperature of the sample during its manipulation was studied first using K-type thermocouples [10]. For this purpose, a hole was drilled in the middle of the sample. The two metal wires of the thermocouple were then welded together and pulled in the borehole towards the middle of the sample (Fig. 1).

Figure 2 shows an example of a temperature measurement with an internal thermocouple. Several temperature phases can be distinguished. For tests above room temperature: three temperature phases can be distinguished. First there is the heating phase in the furnace, where the sample stays during a fixed time span. Secondly we observe a first cooling phase in the air, in front of the temperature measuring device; this second phase ends when the target temperature is reached. At last we have a second cooling phase when the sample is in contact with the two bars; here we find the fastest cooling of the sample (phase 3). The 


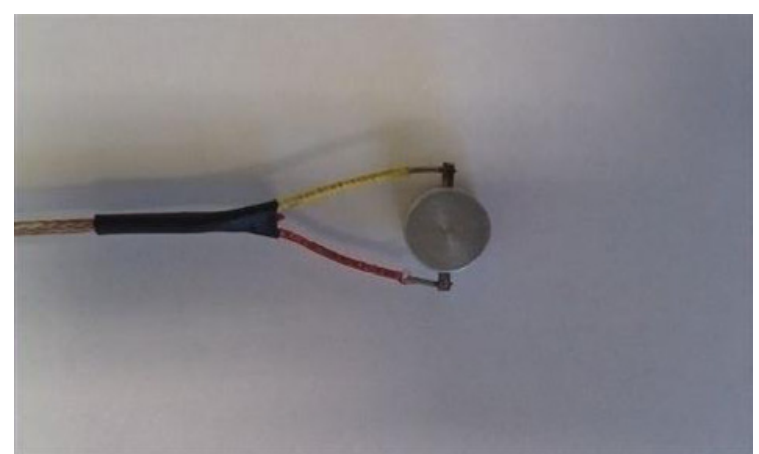

Fig. 1. Thermocouple K-Type inside the sample
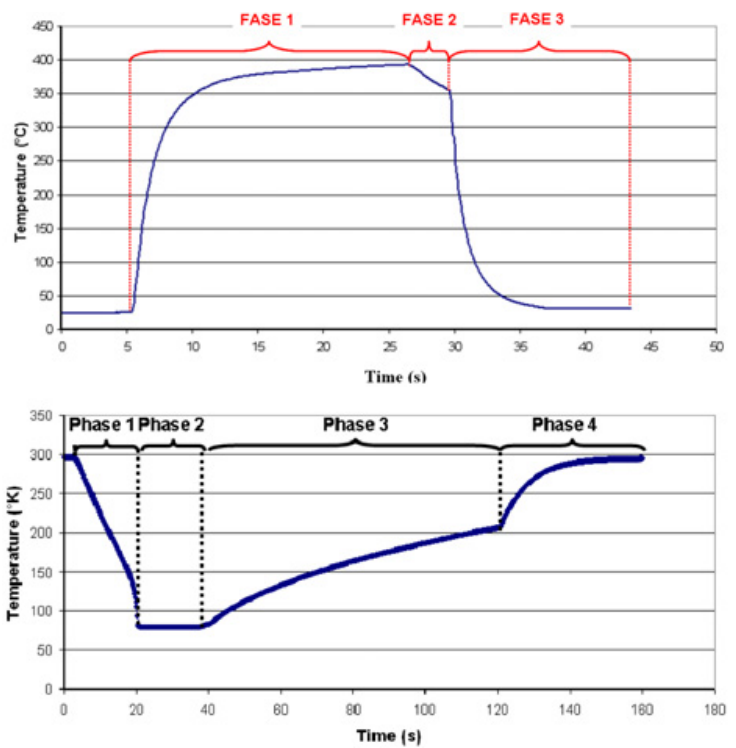

Fig. 2. Example of temperature evolution of a sample.

actual test is initiated one second after the beginning of the phase 3 .

For tests at low temperature, four temperature phases can be distinguished: during phase 1 there is cooling in liquid nitrogen. During phase 2, the sample reaches $77 \mathrm{~K}$ and is kept at this temperature. Phase 3 , is the heating phase in air; this third phase ends when the target temperature is reached. Finally (phase 4), there is a second heating phase when the sample is in contact with the two bars leading to a fast heating of the sample. The dynamic test is initiated after a fixed delay measured after the beginning of phase 4.

For the dynamic Hopkinson tests, it is important to know the temperature at which the test takes place. Therefore it is necessary to study the temperature evolution of the sample between the bars by comparing different models with the measured values, resulting in the choice of a good mathematical predictive model. For these heat transfer models, the radiation is assumed negligible compared to the conductive heat transfer into the bars [9]. Two models were used: a finite element method (ANSYS $®$ ) and a numerical heat transfer model $[9,12]$. Several tests were done at temperatures between $-196^{\circ} \mathrm{C}$ and $350^{\circ} \mathrm{C}$. Details on the models can be found in [11].

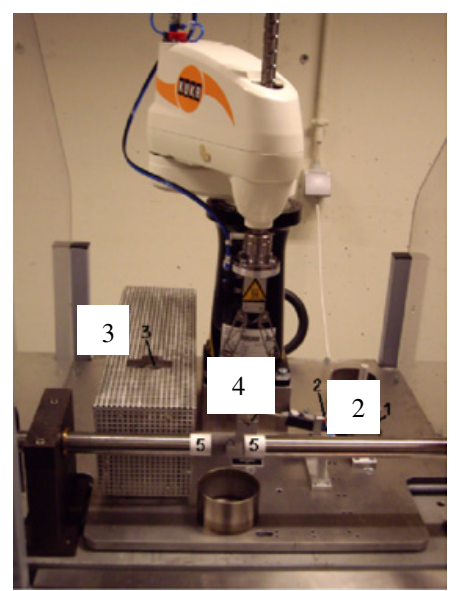

(a)

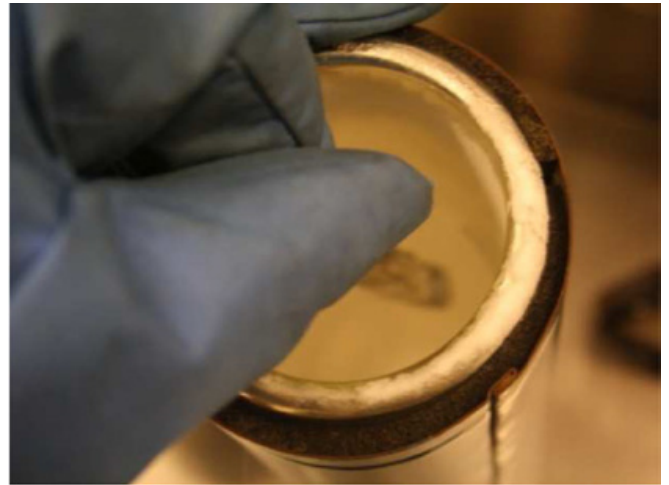

(b)

Fig. 3. (a) The robot (1), the sample pick-up point (2), the furnace (3), the temperature-measuring unit (4) and the SHPB test position (5). (b) Cooling of the sample in the liquid nitrogen

\section{Determination of the constitutive equations}

The objective was to estimate the parameters of three constitutive models.

(a) Johnson-Cook:

$$
\sigma=\left(A+B \varepsilon^{n}\right)\left(1+C \log \frac{\dot{\varepsilon}}{\dot{\varepsilon}_{0}}\right)\left(1-T^{* m}\right)
$$

(b) Zerilli-Amstrong (BCC)

$$
\sigma_{c r i t}=C_{1}+C_{5}(\varepsilon)^{n 1}+C_{2} \exp \left(-C_{3} T+C_{4} T \ln \dot{\varepsilon}\right)
$$

(c) Cowper-Symond:

$$
\sigma=\sigma_{\text {stat }}\left(1+\left(\frac{\dot{\varepsilon}}{D}\right)^{1 / p}\right)
$$

With $\sigma$ the flow stress, $\dot{\varepsilon}$ the strain rate, $\dot{\varepsilon}_{0}$ a reference strain rate, $T^{*}$ given by

$$
T^{*}=\frac{T-T_{r e f}}{T_{m e l t}-T_{r e f}}
$$

The selected temperature for a given test is the temperature derived from the temperature model in the previous 


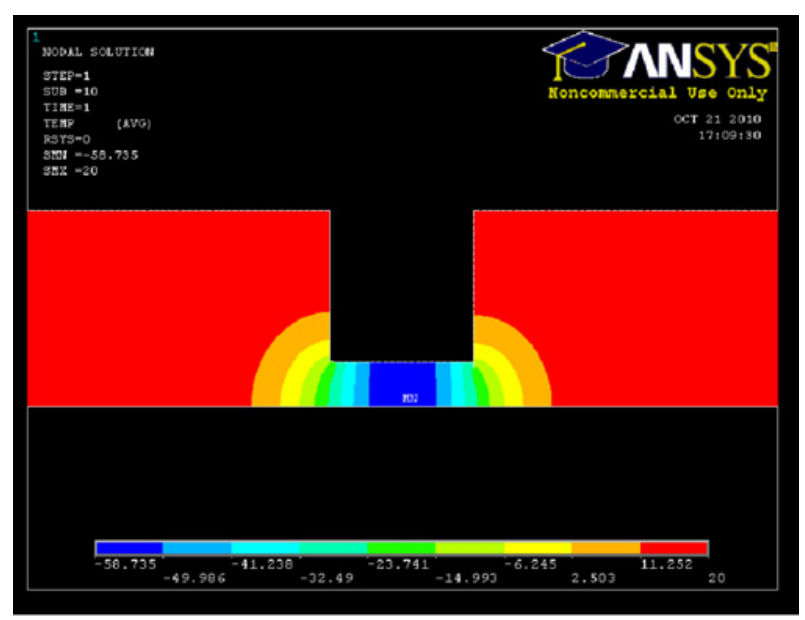

Fig. 4. ANSYS ${ }^{\circledR}$ simulation of the thermal gradient inside a steel alloy sample dimensions of the sample: $11 \mathrm{~mm}$ length $\times 3,5 \mathrm{~mm}$ diameter) - initial temperature: $-100^{\circ} \mathrm{C}, 1 \mathrm{~s}$ between steel bars at room temperature.

Table 1. Johnson-Cook parameters.

\begin{tabular}{|c|c|c|c|c|}
\hline A (MPa) & B (MPa) & C & $m$ & $n$ \\
\hline 1540 & 6590 & 0,058 & 0,86 & 0,03 \\
\hline
\end{tabular}

Table 2. Zerilli-Amstrong parameters.

\begin{tabular}{|c|c|c|c|c|c|}
\hline $\mathrm{C} 1$ & $\mathrm{C} 2$ & $\mathrm{C} 3$ & $\mathrm{C} 4$ & $\mathrm{C} 5$ & $\mathrm{n}$ \\
\hline 2,34E8 & $1,3 \mathrm{E} 9$ & 0,0005 & $1,36 \mathrm{E}-5$ & $7,01 \mathrm{E} 8$ & 0,52 \\
\hline
\end{tabular}

Table 3. Cowper-Symonds parameters.

\begin{tabular}{|c|c|c|}
\hline$\sigma_{\text {stat }}$ & $\mathrm{D}$ & $\mathrm{P}$ \\
\hline $8,61 \mathrm{E} 8$ & 1035,85 & 1,47 \\
\hline
\end{tabular}

paragraph, thus taking into account the cooling/heating between the bars before the actual test. The simulations showed that there is no homogeneous temperature in the sample. Because one temperature is needed in the constitutive equation, the temperature in the sample taken is the temperature in the center of the sample.

We also take into account the temperature rise, due to the adiabatic heating of the specimen, during the plastic deformation, by using following formula [2]:

$$
\Delta T=\frac{\beta}{\rho . c} \int \sigma \cdot d \varepsilon_{p}
$$

Where $\beta$ is a coefficient indicating the fraction of plastic work converted into heat, and taken equal to 0,9 .

Finally the parameters can be found by fitting the data in a least square sense. The results of the fitting are given in table 1,2 , and 3 .

And are valid between $T=-196{ }^{\circ} \mathrm{C}$ and $300^{\circ} \mathrm{C} ; \dot{\varepsilon}$ between 1000 and $2500 \mathrm{~s}^{-1}$. $\mathrm{T}_{\text {ref }}=77 \mathrm{~K}$ and $\dot{\varepsilon}_{0}=1$.

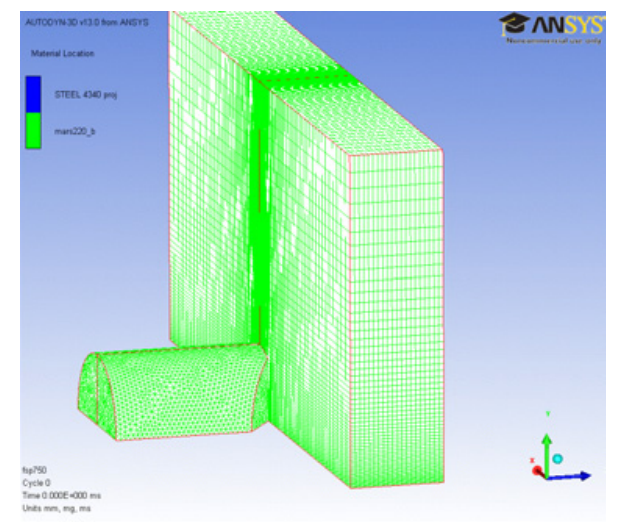

Fig. 5. Simulation of an impact of a FSP.50: initial state.

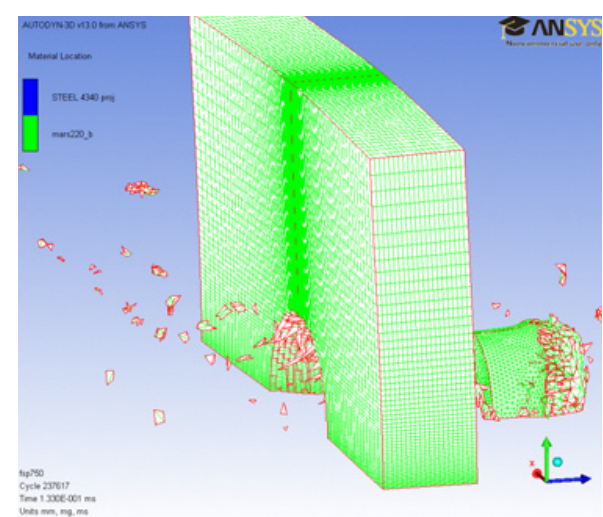

Fig. 6. Simulation of an impact of a FSP.50 with perforation: final state.

\section{Experimental (part 2)}

The ballistic limit V50 was experimentally determined. It gives, for a projectile, the velocity for which there is $50 \%$ chance of perforation. Thirty fragment simulation projectile (FSP) .50 were shot on $8,44 \mathrm{~mm}$ thick plates.

The STANAG method gives a V50 $=598,3 \mathrm{~m} / \mathrm{s}$. The Kneubuehl method gives a V50 $=602,1 \mathrm{~m} / \mathrm{s}$.

When perforation occurs, the residual velocity of the projectile, and the velocity of the plug are measured by a Doppler radar.

\section{Numerical modeling}

In our case, the final perforation of the armor is due to plugging. Almost no cratering was observed and the transition zone of partial to complete perforation showed an abrupt change from only minor indentation of the plate at velocities close to the ballistic velocity, to an almost complete plugging perforation process just above the ballistic velocity. In the case of no perforation, the projectile was completely shattered on the front face of the armor plate. The results of the residual velocity measurement are given in figure 5 .

The simulation was performed using the Johnson-Cook strength model. Validation for other models is in course. 


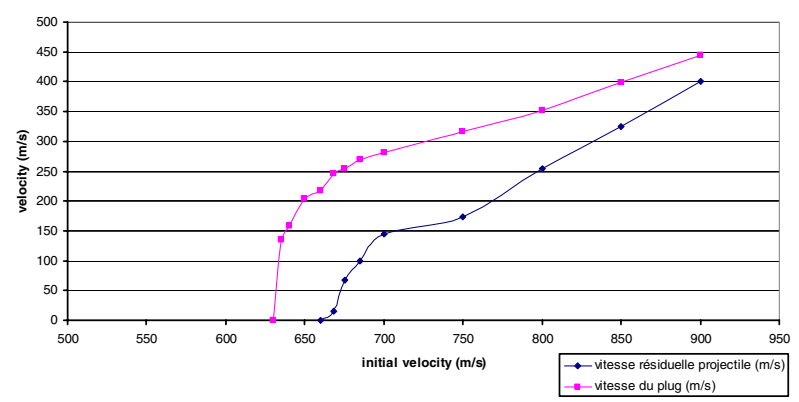

Fig. 7. Simulation of the residual velocities of the FSP and the plug.

The impact of a FSP.50 projectile was simulated. A Lagrangian solver was used for the different parts of the simulation. An axisymmetric model was used in order to reduce the computation time. The ballistic limit velocities determined by numerical modeling is equal to $630 \mathrm{~m} / \mathrm{s}$ quite good comparing to the experimental.

\section{Conclusion}

Different tests have been done: robotized tests for room and high temperature, handling tests for low temperature. The tests were processed at different strain rates, and different temperatures. Simulations showed that the temperature in the samples was not homogeneously distributed. The fitted set of parameters of the constitutive model of Johnson-Cook, Zerilli-Amstrong and Cowper-Symonds is based on dynamic measurements. The parameterization gives good results in a large strain rate and temperature domain. In the near future, a robotized device will be developed for low temperature. The material constants are validated by ballistic tests and its simulation. There is a good correspondence between the tests and computed results. Future works will deal with the measurement with the robotized device at low temperature, with the validation of the obtained material constants, with ballistic tests, simulations and validations at high and low temperature.

\section{References}

1. Lesuer D., Experimental Investigations of Material Model for Ti-6Al-4V Titanium and 2024-T3 Aluminium, US Federal Aviation Administration, William J. Hughes Technical Center's DOT/FAA/AR-00/25, September 2000.

2. Van Slycken J., Advanced Use of a Split Hopkinson Bar Setup (PhD, University of GHENT, 2008).

3. Sasso M., Newaz G. and Amodio D., Materials Science and Engineering (2007).

4. Shazly M., Nathenson D. and Prakash V., Modeling of High-Strain-Rate Deformation, Fracture, and Impact Behavior of Advanced Gas Turbine Engine Materials at Low and Elevated Temperatures (Case Western Reserve University, Cleveland, Ohio, may 2003).

5. Panov V., Modelling of Behaviour of Metals at High Strain Rates $(\mathrm{PhD}$, Cranfield University School of Engineering, 2006).

6. Schwer L., Optional Strain-rate forms for the Johnson Cook Constitutive Model and the Role of the parameter Epsilon_0, LS-DYNA Anwenderforum, Frankenthal, 2007.

7. Lienhard J., A heat transfer textbook, third edition (Phlogiston press, Cambridge Massachussetts, 2008).

8. Meyers M., Dynamic behaviour of materials (Wiley, New York, 1994).

9. Lambrecht R., Determination of material parameters with the Split Hopkinson Pressure Bars at low temperature (Master thesis, Royal Military Academy, Brussels, 2010).

10. Berkovic L. Ryckaert R., Chabotier A. Gilson L., Coghe F. Rabet L., Modeling of high temperature Hopkinson tests on AA5083 and Ti6Al4V, 1663-1668, Proceedings of Dymat (2009).

11. Ryckaert Ruben, Bepalen van materiaalparameters bij hoge temperatuur met de Hopkinson opstelling (Master thesis, Royal Military Academy, Brussels, 2008).

12. Berkovic L, Chabotier A, Coghe F, Rabet L, Measuring and modeling of low temperature Hopkinson tests, Proceedings of ICM11 (2011) 